\title{
NECESSIDADES DE ESTUDANTES UNIVERSITÁRIOS PARA IMPLANTAÇÃO DE UM SERVIÇO DE ORIENTAÇÃO E EDUCAÇÃO EM SAÚDE MENTAL*
}

\author{
Rosely Moralez de Figueiredo** \\ Maria Antonia Paduan de Oliveira***
}

A atenção à saúde dos estudantes universitários é enfocada principalmente com caráter curativo. Este estudo abordou as reais necessidades destes alunos, no que se refere a saúde mental. A prática orientacional e educacional em saúde mental foi implantada na forma de um serviço de atendimento individual e de palestras abordando o tema. O projeto colheu dados e informações necessárias para a efetiva institucionalização desse serviço.

UNITERMOS: saúde mental, saúde do estudante universitário

\section{INTRODUÇÃO}

A atenção à saúde, no que se refere ao atendimento, é dividida, quer seja por sexo, idade, etapas da vida ou ambientes. Essa visão fragmentada da saúde leva a não abrangência total do ser humano nos seus diferentes estágios de vida. Neste sentido, no Brasil, observa-se que a saúde do estudante universitário esta ainda descoberta, urna vez que este não se enquadra em nenhum grupo de atenção em saúde já estabelecido pelos Serviços Básicos de Saúde. Alguns estudos têm demonstrado a presença do interesse dos alunos universitários pela questão "saúde". Apesar disso, serviços dessa natureza são precários e destinados quase exclusivamente ao atendimento de problemas físicos ${ }^{1,7,15,17,18,21,24}$.

\footnotetext{
* Trabalho aceito para apresentação o em ENFERMERÍA, 91, Cuba

** PG - Saúde Mental, Departamento de Psiquiatria e Medicina Preventiva, Faculdade de Ciências Medicas, Universidade Estadual de Campinas

*** Professora do Departamento de Enfermagem Universidade Federal de São Carlos
} 
O estudante, ao ingressar na universidade, passa por situações de crises acidentais ${ }^{5}$, uma vez que sai do seu ambiente familiar e se depara com um mundo desconhecido podendo viver vários conflitos. Isto gera um desequilíbrio emocional, decorrente da insegurança surgida nessas novas relações, A não superação desta crise, decorrente da não adaptação as novas vivências ou ao novo ambiente, poderá se constituir para o aluno em um fator causador de estresse, gerando problemas orgânicos, dificuldades de relacionamento, baixa produtividade escolar, angústias, estados de depressão, apatia e, em situações mais acentuadas, ocorrer perda do interesse pela vida, que o leva ao suicídio ${ }^{8,9,10,12,13}, \mathrm{AZZI}^{2}$ refere que $15 \%$ das pessoas que sofrem de estado depressivo correm o risco de morrer por suicídio, e LIPPI ${ }^{14}$ situa o suicídio como a segunda causa de morte entre estudantes universitários. Em situações menos graves, o aluno universitário pode não entrar em depressão, mas viver constantemente em estados de tensão oriundos da própria situação acadêmica,

As alterações emocionais podem ser resolvidas através de conversa franca e aberta com alguém que demonstre interesse e preparo, constituindo-se assim um método benéfico de ajuda ${ }^{22}$. Essa ajuda poderá ser prestada por diferentes profissionais e não exclusivamente por psiquiatra, uma vez que as crises ocorrem em pessoas sadias ${ }^{3,4,7,13,21}$. D'ANDREA enfatiza que qualquer pessoa pode perceber uma alteração comportamental em si mesmo ou em um companheiro e saber encaminhar-se ou encaminhar outrem para receber auxílio. As relações de ajuda devem ocorrer preferencialmente através de profissões já preocupadas com o bem estar do ser humano, sendo a enfermagem, certamente, uma dessas profissões $6,15,16$

Com o objetivo inicial de conhecer os reais interesses e necessidades do corpo discente da Universidade Federal de São Carlos (UFSCar), no que se refere ao assunto saúde, e com a finalidade de viabilizar a implantação de um Programa de Educação em Saúde, realizamos um estudo prévio (Anexo I). Constatamos que os interesses dos alunos se concentravam em: problemas emocionais (37\%), doenças sexualmente transmissíveis (24 \%), toxicomania $(17,4 \%)$, métodos anticoncepcionais $(10,7 \%)$ e alcoolismo $(2,6 \%)$. Com base nisto, organizamos o presente trabalho, objetivando a implantação de um serviço de orientação e educação em saúde para estudantes universitários, com ênfase em saúde mental, Estes dados iniciais visam subsidiar a implantação, a longo prazo, de um serviço permanente de atendimento nesse nível. O estudo também objetivou esclarecer e orientar individualmente os alunos que procuraram o serviço, através de atendimentos, encaminhá-los para serviços especializados de saúde mental, e fornecer informações por meio de palestras sobre os principais problemas emocionais, de modo que saibam identificá-los e como proceder.

\section{METODOLOGIA}

O estudo foi realizado junto ao corpo discente da Universidade Federal de São Carlos (UFSCar), localizada no interior do Estado de São Paulo, com cerca de 30 cursos e aproximadamente 3.500 alunos. A maioria dos alunos procede de outras cidades. 
Para divulgação do serviço utilizaram-se cartazes e mensagens no jornal de circulação interna da universidade. Na elaboração dos cartazes e mensagens, optamos pelo uso da sigla SOES (Serviço de Orientação e Educação em Saúde), devido a estigmatização que o termo saúde mental poderia produzir no "campus".

Os alunos que procuravam o serviço de orientação eram atendidos em salas individuais, pelas autoras do trabalho, com posterior supervisão de docentes dos Departamentos de Enfermagem e Terapia Ocupacional. O atendimento se processou através de entrevistas, no período de 20.03 .89 a 27.04.89 e recomeçou, após uma greve, do dia 17.07.89 ate 06.09.89. O aluno chegando ao serviço era atendido para agendamento, marcado o horário, este era informado de que o conteúdo do diálogo seria sigiloso e que ele disporia de aproximadamente $45 \mathrm{~min}$ para a entrevista. Durante a entrevista eram esclarecidas as dúvidas à respeito do serviço e discutida a procura pelo SOES. A abordagem utilizada era o oferecimento de esclarecimentos e discussão da queixa apresentada, de forma a funcionar como um referencial de apoio, com o fornecimento de provisões que facilitariam o próprio indivíduo enfrentar o problema. A conduta seguinte dependeria de cada caso, sendo: encaminhamento para outros serviços, agendamento para retornos, ou dispensa sem compromisso de retorno. Ainda era solicitado endereço ou outra forma para contato com o aluno, e a necessidade do retomo no final do semestre para avaliação da orientação. Os encaminhamentos poderiam ser feitos aos: Serviço de Psiquiatria do Centro de Saúde da cidade, Serviço Ambulatorial de Terapia Ocupacional da UFSCar e consultórios particulares. O aluno avaliaria o serviço através de um instrumento, onde analisaria desde o horário, local, entrevistas, até a necessidade de continuidade do SOES (Anexo II). Esse instrumento de avaliação era entregue aos alunos na última entrevista e recolhidos em seguida.

No dia 23.08.89 realizamos uma mesa redonda debatendo o tema "Saúde Mental do Estudante Universitário", que contou com a participação de setenta e três alunos de graduação. A avaliação do evento foi realizada através de um instrumento contendo 3 questões que avaliaram o tema apresentado, a dinâmica utilizada e as opiniões dos alunos sobre outros temas de interesse dos mesmos na referida área. Após o preenchimento, os instrumentos foram recolhidos e separados em grupos de acordo com o núcleo das respostas.

\section{RESULTADOS}

Procuraram o serviço um total de nove alunos, sendo três homens e seis mulheres. Cinco freqüentavam cursos da área de Ciências Exatas e quatro da área de Saúde. Quanto ao tempo na universidade, dois eram calouros, dois segundanistas, três terceiro-anistas, um quartanista, e um transferido de outra universidade, perfazendo um total de 28 entrevistas. A seguir, são descritas, resumidamente, a história de cada aluno e a conduta tomada em cada caso: 


\section{E.C.S. - 22 anos - área saúde}

A aluna procurou o serviço devido a conflitos com o namorado e sentir necessidade de desabafar com alguém. A situação do namoro era bastante complexa, mas a aluna já tinha em sua cabeça quais as coisas que deveriam mudar para que o relacionamento pudesse dar certo e, embora o namorado concordasse com isso, ele não estava disposto a tanto. O SOES funcionou, portanto como um reforço para a aluna manter-se firme em sua decisão que culminou posteriormente com o término do namoro. No final de 4 entrevistas a aluna referia estar segura da decisão tomada, embora ainda sofresse muito e começava fazer planos para a vida profissional.

\section{P. - 19 anos - área exata}

Procurou o serviço para obter informações sobre terapias prestadas, uma vez que já se submeteu a terapias anteriores, para resolver um problema de "depressão" que sofre há 7 anos. Foram mostradas as alternativas disponíveis e o aluno interessou-se pelo serviço ambulatorial de terapia ocupacional. Ele foi encaminhado para o serviço e mesmo assim continuou procurando o SOES para discutimos como estava sendo sua evolução. Discutimos sobre medicação antidepressiva, a participação do paciente na terapia e assuntos diversos sobre a universidade. No final de 7 entrevistas, ele refere estar fazendo terapia, embora não consiga ver como ela poderá ajudá-lo a resolver a depressão e aceita que e um processo muito lento.

\section{S.T.S. - 20 anos - área exatas}

Procurou o SOES referindo não estar bem, sentindo-se muito angustiada. Sentia-se sozinha e incompreendida pelo ex-namorado e pelos amigos. Durante a primeira entrevista chorou muito e sentiu-se muito melhor por isso. O SOES atuou apoiando a exteriorização dos sentimentos da aluna, de forma que ela deixou emergir emoções que nunca haviam vindo a tona anteriormente. No final de 3 entrevistas, a aluna sentia-se muito mais segura e compreensiva com tudo que estava acontecendo com ela. Conseguia levantar pontos de sua vida que necessitariam de mudanças, entretanto ainda não sentia-se disposta a fazê-lo.

4. M. - 30 anos - área exatas

Procurou o SOES por estar muito confusa entre curso, marido, filhos e emprego. Estava também com muitas dúvidas a respeito de trancamento de matrícula, reprovação em disciplinas, pré-requisitos etc. O SOES forneceu todas as orientações burocráticas possíveis e orientou que antes de tomar qualquer decisão nesse sentido procurasse o coordenador de curso e a DICA (Divisão de Informação e Controle de Alunos), além de permitir um alívio da ansiedade da aluna através da entrevista. Ao final de 3 entrevistas, a aluna refere estar conciliando melhor todas as suas responsabilidades, embora não esteja indo muito bem nas disciplinas; sente-se entretanto segura na forma como dividiu seu tempo entre família e estudo.

\section{I. - 21 anos - área saúde}

Procurou o SOES referindo apatia e desinteresse pelo curso, pois devido a problemas burocráticos a aluna ficaria 1 ano sem freqüentar o curso por falta de disciplinas oferecidas à ela, somando-se ainda problemas familiares antigos. Foi constatado que o problema principal 
era a ociosidade do ano referido e quando questionada sobre opções de atividades (estágios, cursos etc.) a aluna refere se interessar apenas por atividades em ambiente hospitalar e esta oportunidade não the foi oferecida. O SOES interveio junto a docentes do departamento envolvido e estes junto a instituições da cidade e a aluna conseguiu trabalho no local. A aluna refere estar muito animada com o trabalho que the dará condições de se subsidiar e fornecimento de aportes suficientes para passar o ano sem disciplinas.

6. E. - 22 anos - área exatas .

Procurou o SOES queixando-se de dificuldades de concentração para estudar. Foram discutidas várias hipóteses, desde saúde física (alimentação, parasitose) até estafa, estresse. Somando-se a isso existia um problema de timidez diante de relacionamento afetivo novo. Durante as entrevistas foram levantados pontos como o número de atividades que o aluno acumula, a grande expectativa em relação a ele mesmo, que poderia ocasionar excesso de rigidez nos resultados de seus atos, entre outros. O aluno foi encaminhado ao serviço de T. 0 . para acompanhamento terapêutico e não retomou ao SOES para comunicar os resultados e responder o instrumento de avaliação.

7. R. - 23 anos - área saúde

Procurou o SOES para fazer terapia, pois referiu sentir-se muito insegura e que experiências com terapias anteriores produziram bons resultados. Foi discutido como se processava a insegurança e alternativas de terapias disponíveis. A aluna optou pelo serviço de Terapia Ocupacional e iniciou contato com este. Não retomou ao serviço para responder o instrumento de avaliação.

8. J. - 20 anos - área saúde

Procurou o SOES encaminhada pela coordenadora do seu curso. É uma aluna estrangeira, vinda da Bolívia e totalmente inapta a nova situação. Refere Ter vindo ao Brasil para "fugir" de problemas com a família e namorado e para isto se sujeitou a aceitar o único curso que possuía vaga, embora já soubesse que não gostava da área escolhida, que se impressionava muito com pessoas doentes, dor, etc. Seu objetivo era fazer computação na Bolívia e isto tudo estava lhe causando grande angústia. Durante as entrevistas foi discutido muito o que significaria para ela voltar a Bolívia, o que é realmente o seu curso ( oferecendo inclusive oportunidade de conhecer profissionais em campo de trabalho), quais são seus medos, entre outros. No final da terceira entrevista a aluna refere estar muito mais tranqüila:, com maior clareza para pensar e segura em terminar o semestre, ir para casa nas ferias e lá, juntamente com sua família, decidir o que irá fazer.

9. Pa. - 20 anos - área exatas

Procurou o SOES após informação de amigos que participaram da mesa redonda. Refere falta de concentração nos estudos. Tranqüilizado a respeito de que essa situação é plenamente normal, que apenas uma fase, uma vez que ele encontrava-se muito preocupado achando que estava com problemas psicológicos graves. Ficou combinada uma próxima entrevista, que não aconteceu.

As respostas ao instrumento de avaliação encontram-se no Quadro 1. 


\section{QUADRO 1 - RESPOSTAS DOS ALUNOS QUE PROCURARAM O ATENDIMENTO INDIVIDUALIZADO DO SOES AO INSTRUMENTO DE AVALIAÇÃO}

\begin{tabular}{|c|c|c|}
\hline Perguntas & Respostas & $\mathbf{n}$ \\
\hline $\begin{array}{l}\text { P1 - Como você tomou } \\
\text { conhecimento da existência do } \\
\text { serviço? }\end{array}$ & $\begin{array}{l}\text { - Através da entrevista. } \\
\text { - Filipetas na biblioteca. } \\
\text { - Cartaz afixado no campus. } \\
\text { - Jornal da Federal. } \\
\text { - Coordenador do curso }\end{array}$ & $\begin{array}{l}1 \\
2 \\
3 \\
1 \\
1\end{array}$ \\
\hline $\begin{array}{l}\text { P2 - O serviço atendeu a sua } \\
\text { expectativa? }\end{array}$ & $\begin{array}{l}\text { - Sim. } \\
\text { - Em partes. É necessário um número maior de } \\
\text { profissionais especializados. }\end{array}$ & $\begin{array}{l}5 \\
1\end{array}$ \\
\hline $\begin{array}{l}\text { P3 - Quais pontos deixaram a } \\
\text { desejar em relação ao serviço? }\end{array}$ & $\begin{array}{l}\text { - Horário. } \\
\text { - Um número muito pequeno de pessoas tomou } \\
\text { conhecimento do serviço. } \\
\text { - Nenhum. }\end{array}$ & $\begin{array}{l}2 \\
1 \\
3\end{array}$ \\
\hline $\begin{array}{l}\text { P4 - Quais pontos contribuíram } \\
\text { para a eficiência do serviço? }\end{array}$ & $\begin{array}{l}\text { - Horário. } \\
\text { - Atendimento do entrevistador. } \\
\text { - Local. } \\
\text { - Forma como foi desenvolvido. } \\
\text { - Destino dos encaminhamentos. }\end{array}$ & $\begin{array}{l}4 \\
4 \\
5 \\
1 \\
2\end{array}$ \\
\hline $\begin{array}{l}\text { P5 - O que você acha da } \\
\text { continuidade do SOES? }\end{array}$ & $\begin{array}{l}\text { - Necessário da forma como está. } \\
\text { - Necessário, entretanto deve ser reformulado. Deve ser } \\
\text { mais divulgado entre alunos, funcionários e professores. }\end{array}$ & $\begin{array}{l}3 \\
2\end{array}$ \\
\hline \multirow[t]{5}{*}{ P6 - Comentários e sugestões } & - Nenhum. & 2 \\
\hline & $\begin{array}{l}\text { - "Acredito que esse tipo de trabalho é muito importante } \\
\text { dentro de uma universidade, onde um mesmo local dentro } \\
\text { de uma universidade, onde num mesmo local encontramos } \\
\text { pessoas tão divergentes, situações novas, tensão, entre } \\
\text { outras dificuldades. Torço para que o serviço tenha } \\
\text { continuidade e seja bastante recompensador para seus } \\
\text { criadores. Sugiro que se encontre um meio, infelizmente não } \\
\text { tenho em mente qual, que o serviço seja mais conhecido } \\
\text { dentro e fora da universidade". }\end{array}$ & 1 \\
\hline & $\begin{array}{l}\text { - "É um serviço válido, pois tem-se uma pessoa para } \\
\text { conversar, alguém que no momento em que alguma coisa } \\
\text { vai mal ela esteja preparada psicologicamente, podendo nos } \\
\text { ajudar, nem que seja só para ajudar escutando". }\end{array}$ & 1 \\
\hline & $\begin{array}{l}\text { - "O SOES deveria funcionar por mais tempo, e também } \\
\text { num local só para ele. Fui apenas para conversar, acabei } \\
\text { desabafando e quando saí, parecia mais leve, como se } \\
\text { metade dos problemas estivesse extinta. O SOES deve } \\
\text { continuar. Muita gente não tem alguém com quem } \\
\text { conversar, principalmente os alunos. Os colegas são muitos, } \\
\text { porém amigos são poucos". }\end{array}$ & 1 \\
\hline & $\begin{array}{l}\text { - "Gostei muito porque é uma experiência para a pessoa que } \\
\text { tem um problema, pois pode conversar com alguém } \\
\text { sentindo-se aliviada e tranqüila. }\end{array}$ & 1 \\
\hline
\end{tabular}


De forma geral, os alunos que procuraram o SOES externaram que o serviço atendeu as expectativas, que o horário, local e atendimento do entrevistador foram pontos que contribuíram para a eficiência do serviço e que e necessário a sua continuidade. Todo o material completo e original foi guardado em arquivo do SOES, que servirá posteriormente como fundamentação para a pesquisa e desenvolvimento do serviço.

Quanto ao debate sobre a saúde mental do estudante universitário, compareceram na maioria alunos ingressantes praticamente de todas as áreas de estudo. As respostas ao instrumento de avaliação estão agrupados nos QUADROS 2 e 3.

QUADRO 2 - RESPOSTAS DOS ALUNOS QUE PARTICIPARAM DA MESA REDONDA SOBRE "SAÚDE MENTAL DOS ESTUDANTES UNIVERSITÁRIOS", AO SEREM QUESTIONADOS SE GOSTARAM OU NÃO DO TEMA ABORDADO

\begin{tabular}{|l|c|}
\hline \multicolumn{1}{|c|}{ Respostas e respectivas justificativas } & $\mathbf{n}$ \\
\hline \multicolumn{1}{|c|}{ SIM } & 67 \\
\hline - Discutiu assunto que afeta a vida de todos. & 25 \\
- Discutiu assunto do dia-a-dia do universitário. & 14 \\
- Divulgou assunto de grande interesse dos alunos. & 10 \\
- Esclarecimentos sobre problemas enfrentados. & 6 \\
- Divulgou o serviço existente na universidade. & 4 \\
- Porque o tema foi sempre tratado com preconceito. & 3 \\
- Demonstrou interesse com o comprometimento humano. & 2 \\
- Forneceu noções de como enfrentar problemas. & 1 \\
- Forneceu base para uma vida melhor. & 1 \\
- Estimulou o auto-conhecimento. & 1 \\
\hline \multicolumn{1}{|c|}{ NÃo } & 5 \\
\hline - Assunto muito complexo. & 1 \\
- Aprofundou muito na psicanálise. & 1 \\
- Não possui vínculo com a área do aluno interrogado. & 1 \\
- A entrada na universidade não causa perturbação psíquica. & 1 \\
- O tema está saturado & 1 \\
\hline
\end{tabular}




\section{QUADRO 3 - RESPOSTAS DOS ALUNOS QUE PARTICIPARAM DA MESA REDONDA SOBRE "SAÚDE MENTAL DOS ESTUDANTES UNIVERSITÁRIOS", AO SEREM QUESTIONADOS SOBRE QUAIS TEMAS DESSA MESMA ÁREA GOSTARIAM DE CONHECEREM MAIS PROFUNDAMENTE}

\begin{tabular}{|l|c|}
\hline \multicolumn{1}{|c|}{ Assuntos } & $\mathbf{n}$ \\
\hline - Saúde mental (loucura, crises, como enfrentar problemas, estresse, psicologia & 21 \\
manicômios etc.). & \\
- Saúde (física e mental). & 7 \\
- Problemas ligados aos universitários. & 7 \\
- AIDS. & 6 \\
- Educação sexual. & 5 \\
- Informações sobre o serviço de saúde da UFSCar. & 3 \\
- Comportamento humano. & 3 \\
- Não responderam. & 16 \\
\hline - Total & $\mathbf{7 1}$ \\
\hline
\end{tabular}

Noventa e dois por cento dos alunos demonstraram terem gostado do tema abordado (Quadro 2), Vinte e nove por cento dos alunos gostariam de saber mais sobre temas de saúde mental, tais como loucura, crises e estresse (Quadro 3).

\section{DISCUSSÃO E CONCLUSÃO}

A procura do SOES pelos alunos e as respostas obtidas na avaliação da mesa redonda, confirmam outros estudos ${ }^{1,18,24}$, nos quais os alunos demonstraram interesse em adquirir informações sobre saúde e, em especial, orientações psicológicas.

Com os resultados das entrevistas, consideramos que os problemas apresentados pelos alunos podem na maioria das vezes ser resolvido pelo próprio indivíduo. Contudo, esta capacidade de resolução pode ser muito facilitada com o estabelecimento de uma relação de ajuda com um profissional, uma vez que os problemas apresentados se restringiram a problemas afetivos com namorados e família; e problemas institucionais, como dúvidas a respeito de pré-requisitos, trancamento de matrículas e vida profissional. Entretanto, isso não significa que sejam problemas inconseqüentes para o aluno ${ }^{19,20}$. GIGLIO ${ }^{11}$ refere que os alunos, atendidos no Serviço de Higiene Mental para estudantes da Universidade Federal de Pernambuco, informam que as dificuldades emocionais prejudicam o rendimento nos estudos e, conseqüentemente, na vida profissional futura. 
Segundo D'ANDREA ${ }^{7}$, na comunidade universitária todos estão sujeitos a crises de identidade, entretanto a população dos estudantes e a mais susceptível. CAPLAN ${ }^{5}$ cita que a crise e um período de transição que pode ser tanto uma oportunidade de crescimento da personalidade, como um período de maior vulnerabilidade ao transtorno mental, e o resultado final desse período depende da forma como o indivíduo enfrenta a situação. A intervenção nesse período, ou seja, fornecimento de aportes (provisões) e expansão de alternativas para a resolução do problema, é o ponto decisivo para se evitar um transtorno mental provindo de crises não resolvidas ${ }^{5,23}$.

Os achados do presente trabalho, apesar de limitados à primeira vista pelo pequeno número de alunos que procuraram o serviço, são, entretanto, fundamentais para o início de um estudo e pesquisa mais aprofundados sobre quais são os reais problemas da população universitária. Este estudos são importantes, uma vez que no Brasil existem poucos trabalhos sobre saúde mental do estudante universitário provindos da população comum e não do atendimento psiquiátrico, sendo esses fundamentais para a Psiquiatria Preventiva ${ }^{11,15}$.

Diante dos dados encontrados nas entrevistas, podemos indicar três tipos de intervenções básicas a serem desenvolvidas em uma universidade que pretenda atender as necessidades dos alunos na esfera de saúde mental: aconselhamento, encaminhamentos psicoterápicos e orientação psicopedagógica. Para isso há necessidade de um número maior de profissionais, tais como: psicólogos, enfermeiros, assistentes sociais, educadores e demais profissões de ajuda, formando equipes multiprofissionais e desenvolvendo atividades de atendimento individual e grupal.

Observamos, também, que o número de entrevistas no atendimento individual demonstra o interesse dos alunos pelo serviço, uma vez que a maioria deles, retornou várias vezes aos SOES para orientação, quer seja por solicitação das autoras ou mesmo espontaneamente. Isto também foi reforçado pelas respostas obtidas dos participantes da mesa redonda.

Como o atendimento individualizado não atinge grandes populações, consideramos a promoção de discussões sobre o assunto uma forma de mobilizar atenções. Para isto, é fundamental a institucionalização do programa, ou seja, o SOES passar a fazer parte dos recursos oferecidos aos alunos pela Instituição. Além disso, vimos a necessidade de criação de espaços destinados a essa discussão, quer seja através de cursos, palestras, debates, grupos de vivência e higiene mental ou até mesmo o oferecimento de uma disciplina regulamentada e aberta ao "campus", onde fosse despertado nos alunos o interesse pelo entendimento e manutenção da saúde mental.

O papel do SOES é essencialmente importante para elevar o nível da saúde mental dos estudantes, contribuindo inclusive para o exercício profissional desses alunos. Além disso, oferece interessante campo de pesquisa para alunos e docentes da instituição de ensino. 


\section{AGRADECIMENTOS}

As autoras agradecem Maria Waldenez de Oliveira e Michelle Selma Hahn da Universidade Federal de São Carlos, por valiosas sugestões ao longo do estudo e leitura crítica do manuscrito, a R.A. de Figueiredo da UNICAMP por sugestões quanto a apresentação do texto, e a dois revisores anônimos por valiosas sugestões para melhoria do manuscrito.

\section{ORIENTATION AND EDUCATION IN MENTAL HEALTH FOR UNIVERSITY STUDENTS}

The curative feature of health of university students has gained more attention. This study evaluated the needs of university students for an orientational and educational service on mental health. For mental health orientation and education, an individual consultation service, was implanted as well as lectures about the theme. This project gathered data and information important to the effective institutionalization of the service.

Uniterms: health of university students, mental health

\section{NECESIDADES DE ESTUDIANTES UNIVERSITARIOS PARA IMPLANTACIÓN DE UN SERVICIO DE ORIENTACION Y EDUCACIÓN EN SALUD MENTAL}

La atención a la salud de los estudiantes universitarios es enfocada principalmente con carácter curativo. Este estudio abordo las reales necesidades de los alumnos, en lo que se refiere a la salud mental. La práctica de la orientación y educación en salud mental, fue implantada en la forma de un servicio de atendimiento individual y de reuniones abordando el tema. El proyecto reunió datos e informaciones necesarias para la efectiva institucionalización de ese servicio.

Unitermos: salud del estudiante universitario, salud mental 


\section{REFERÊNCIAS BIBLIOGRÁFICAS}

01. ALMEIDA, M. M. G. et al. Interesse de universitários em aspectos de saúde. Rev. Bras. Enfermagem, v. 33, p. 157-165, 1980.

02. AZZI, E. A depressão mascarada na prática clínica. Clínica Geral. 1979, p. 17-24.

03. BECHELLI, L.P.C. (org.). IV Simpósio integração entre a clínica e psiquiatria. Ribeirão Preto, 1987. p. 103.

04. BELLAK, L.M.D.; SMALL, L. Psicoterapia de emergência \& psicoterapia breve. Porto Alegre: Artes Médicas, 1980.

05. CAPLAN, G. Princípios de psiquiatria preventiva. Trad. de Alvaro Cabral. Rio de Janeiro: Zahar, 1980. p.324.

06. CARVALHO, V. A relação de ajuda e a totalidade da política da enfermagem. In: CONGRESSO BRASILEIRO DE ENFERMAGEM, 32, Brasília, 1980. Anais. Brasília, ABEN, 1980. p. 65-72.

07. D'ANDREA, F. F. .Saúde mental na comunidade universitária./ Apresentado na Semana da Enfermagem, São Carlos, UFSCar, 1983.I

08. D'ASSUMPÇÃO, E. A. Os que partem, os que ficam. Belo Horizonte: O Lutador, 1987. p. 158.

09. D'ASSUMPÇÃO, E. A.; D'ASSUMPÇÃO, G. M.; BESSA, N. A. Morte e suicídio: uma abordagem multiprofissional. Petrópolis: Vozes, 1984, p. 237.

10. ESTRESSE. Rio de Janeiro, Roche, v.7, p. 1-16, s.d.

11. GIGLIO, J. S. Um estudo de fatores biológicos, sociais e ambientais com provável influência no bem-estar psicológico de universitários. Rev.Assoc.Bras.Psiq., v. 3, n. 142-46, s.d.

12. GIKOVATE, F. Você é feliz? Uma nova introdução ao narcisismo. São Paulo: MG Editores, 1978. p. 129.

13. JACOBSON, G. F. Crises: oriented therapy. Psychiatr. Clin. North Philadelphia, v. 2, n. 39-53, 1979.

14. LIPPI, J.R.S. Urgências em neuropsiquiatria infantil. Urgências, v. 6, p. 1-26, 1976.

15. LOFFRED, L. E. Relação de ajuda. In: CONGRESSO BRASILEIRO DE ENFERMAGEM, 32, Brasília, 1980. Anais. Brasília, ABEN, 1980. p. 57-63.

16. MINZONI, M. A. Atitudes do profissional de enfermagem frente a pessoa que requer ajuda. In: ENCONTRO MULTIPROFISSIONAL DE SAÚDE COMUNITÁRIA, I, Campinas, 1979. Anais. Campinas, 1979. p. 10.

17. PARET A, J. M. M. et al. Saúde de comunidade: temas de medicina preventiva e social. São Paulo: McGraw-Hill, 1976. p. 228. 
18. RIBEIRO, M. C. S.; PILOTTO, S. M. Levantamento da necessidade de informações em saúde dos estudantes e funcionários serventes da UFSCar. São Carlos, 1984. p. 25. (mimeografado).

19. SHINY ASHIKI, R. A caricia essencial. Uma psicologia do afeto. São Paulo: Gente, 1989. p. 132.

20. SHINY ASHIKI, R.; DUMET, E. B. Amar pode dar certo. S. L., Dag Gráfica e Editorial, 1988. p. 155.

21. SIMON, R. Psicologia clínica e preventiva: novos fundamentos. Vetor, 1983. p. 230.

22. SIVADON, P.; FERNANDEZ-ZOILA, A. Corpo e terapêutica: uma psicopatologia do corpo. Campinas: Papirus, 1988. p. 284.

23. TRICK, L.K.; OBCARSKAS, S. Understanding mental illness and its nursing. London: Pitman Press, 1976. p.285.

24. VAZ, A.F.; SANTOS, V. Implantação de um serviço de orientação sexual na Universidade Federal de São Carlos. São Carlos, 1986. p. 13. (mimeografado). 


\title{
ANEXO I - QUESTIONÁRIO APLICADO AOS ALUNOS PARA EXTERIORIZAÇÃO DAS SUAS NECESSIDADES EM RELAÇÃO AO TEMA SAÚDE
}

\section{UNIVERSIDADE FEDERAL DE SÃO CARLOS DEPARTAMENTO DE ENFERMAGEM}

\begin{abstract}
Com o propósito de viabilizar a implantação de um Programa de Educação e Atendimento em Saúde, solicitamos sua colaboração no sentido de indicar qual o tema/serviço na sua opinião seria prioritário.
\end{abstract}

01 - Para tanto, enumere em ordem crescente as prioridades (1-6):

( ) uso de métodos anticoncepcionais

( ) doenças transmitidas sexualmente (sífilis, gonorréia, AIDS, etc.)

( ) alcoolismo

( ) toxicomania

( ) problemas emocionais (depressão, angústia, etc.)

( ) outros. Quais?

02 - Na sua opinião de que forma as informações poderiam ser dadas?

( ) orientações individuais; ( ) cursos; ( ) folhetos;

( ) outros. Quais?

03 - Na sua opinião qual seria o melhor horário para o desenvolvimento

04 - Curso que você freqüenta turma 


\section{ANEXO II - INSTRUMENTO DE AVALIAÇÃO DO SERVIÇO}

01 - Como você tomou conhecimento da existência do serviço?

( ) cartaz afixado no campus; ( ) filipetas na biblioteca;

( ) intermédio de outras pessoas; ( ) outros. Quais?

02 - O serviço atendeu a sua expectativa?

( ) $\operatorname{sim}($ ) não ( ) em partes. Por que?

03 - Quais pontos deixaram a desejar em relação ao serviço?

( ) horário ( ) local ( ) forma como ele foi desenvolvido

( ) atendimento do entrevistador ( ) outros. Quais?

( ) destino dos encaminhamentos

04 - Quais pontos contribuíram para a eficiência do serviço?

( ) horário ( ) local ( ) forma como ele foi desenvolvido

( ) atendimento do entrevistador ( ) outros. Quais?

( ) destino dos encaminhamentos

05 - O que você acha da continuidade do SOES?

( ) desnecessário ( ) necessário da forma como está

( ) necessário, entretanto deve ser reformulado

( ) outros. Quais? 